\title{
A Microwave-assisted Domino Rearrangement of Propargyl Vinyl Ethers to Multifunctionalized Aromatic Platforms
}

\author{
David Tejedor, ${ }^{[a][b]}$ Gabriela Méndez-Abt, ${ }^{[a][b]}$ Leandro Cotos, ${ }^{[a][b]}$ Miguel A. \\ Ramirez $^{[\mathrm{c}]}$ and Fernando García-Tellado*[a][b]
}

In memoriam of Professor Rafael Suau

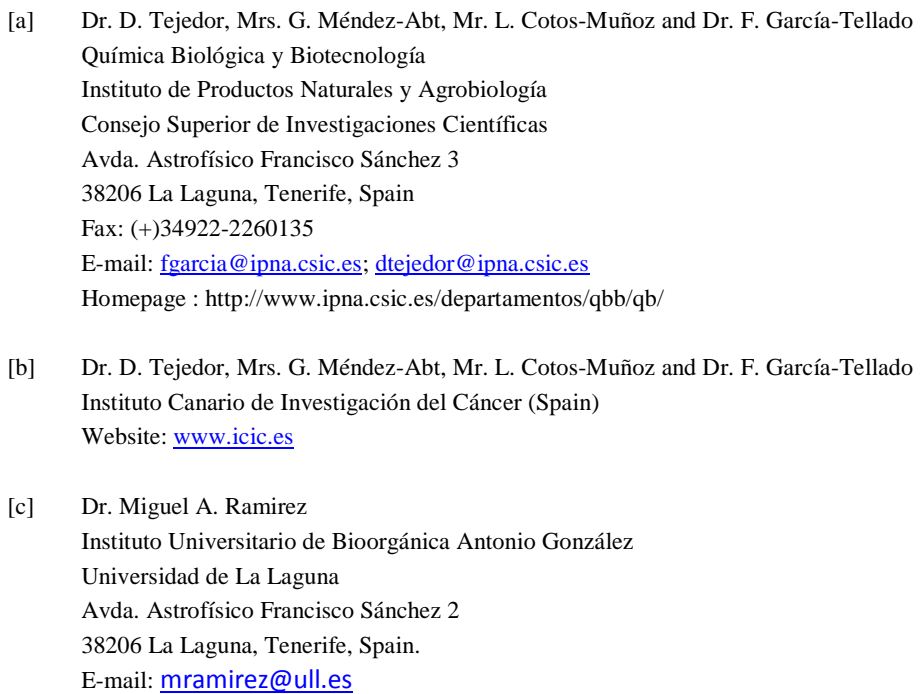

Abstract: Readily available propargyl vinyl ethers can be efficiently converted into convenient multifunctionalized aromatic products via a microwave-assisted and novel domino process involving at least seven differentiated events (propargyl Claisen rearrangement; pseudopericyclic $[1,3] \mathrm{H}$ shift; double bond isomerization, $[1,5] \mathrm{H}$ shift; enolization; electrocyclization and aromatization). This unprecedented reaction represents a new chemical reactivity profile for these propargylic platforms. In addition, the reaction products include salicylaldehyde derivatives and alkyl (or aryl) 2hydroxyphenyl ketone derivatives armed with a wide and diverse functional group pattern decorating the ring.

Propargyl vinyl ethers (PVEs) 1 constitute a privileged group of small size, structurally simple, readily available and densely functionalized scaffolds. ${ }^{[1-4]}$ Efforts from our group ${ }^{[2]}$ and others ${ }^{[3]}$ have shown the synthetic potential of these platforms in accessing important heterocyclic cores. The key to the chemical reactivity encoded in these structures is the [3,3] propargylic sigmatropic rearrangement ${ }^{[5]}$ shown in [Eq. (1)]. The allenyl compounds $\mathbf{2}$ thus obtained are reactive units well suited to participate in a wide array of chemical transformations. Thus, in the presence of metallic catalysts, they 
have been selectively transformed into furans, ${ }^{[3 \mathrm{a}-\mathrm{d}]} 2 \mathrm{H}$-pyrans, ${ }^{[3 \mathrm{e}]}$ dihydropyrans, ${ }^{[3 \mathrm{f}]} 1,2-$ dihydropyridines $^{[3 \mathrm{~g}]}$ or pyrroles. ${ }^{[3 \mathrm{~h}]}$ Recently, we have described ${ }^{[2 \mathrm{c}, \mathrm{d}]}$ a metal-free, microwave-assisted domino synthesis of substituted 1,2-dihydropyridines ${ }^{[2 \mathrm{c}]}$ and pyridines, ${ }^{[2 \mathrm{~d}]}$ from PVEs 1 and primary amines, via the thermally-assisted formation of an homoallenyl ester intermediate 2. During the course of these studies, we discovered a new chemical reactivity of these platforms when a solution of PVE 3a in toluene was submitted to microwave (MW) irradiation in a sealed vial (Scheme 1). The reaction cleanly afforded the unexpected mixture of compounds $\mathbf{4 a}$ and $\mathbf{5 a}$ in $91 \%$ overall yield. These structures featured an unprecedented chemical outcome for this domino process, which is enabled by the presence of a hydrogen atom at the homopropargylic position (see below). Fascinated by these unexpected results, we undertook the study and scope of this novel domino reaction. Overall, this reaction should provide an expedient route to useful multifunctionalized phenolic platforms ${ }^{[6]} \mathbf{4}$, which constitute key structural motifs for the preparation of numerous pharmacologically important natural products (e.g. coumarins, ${ }^{[7 \mathrm{a}]}$ flavones ${ }^{[7 \mathrm{~b}]}$ and several mycotoxins,${ }^{[7 \mathrm{c}]}$ ) and catalysts. ${ }^{[8]}$ In addition, PVEs 3 are easily accessible starting materials spanning a wide substitution pattern. They are conveniently assembled from commercial sources (aldehydes, alkynes and alkyl propiolates) in one or two straightforward synthetic steps. ${ }^{[2]}$

We hypothesized that the formation of products $4 \mathbf{a}$ and $\mathbf{5 a}$ should result from a domino process triggered by the expected microwave-assisted rearrangement of PVE $3 \mathbf{a}$ to the corresponding dienic ester 7a via the formation of a transient homoallenyl ester 6a. ${ }^{[9]}$ A subsequent tandem cyclization-aromatization reaction should afford the corresponding phenolic derivatives 4a with the concomitant elimination of one equivalent of methanol. Addition of this liberated methanol on the intermediate $7 \mathbf{a}$ should trigger a second reaction path affording the product 5a via the formation of hemiacetal 8a. In this scenario, it was expected that the removal of the generated methanol should funnel the whole transformation toward the exclusive formation of $\mathbf{4 a}$. With this idea, we designed an experimental protocol including in the reaction mixture

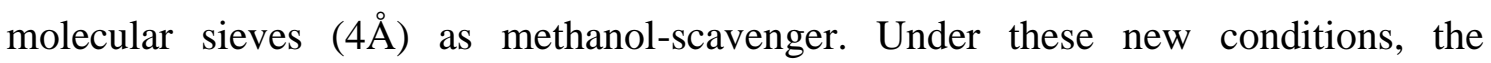
formation of the malonate derivative 5a was totally suppressed. After several experiments, the reaction was standardized, and scaffold 3a was conveniently converted into the salicylaldehyde $\mathbf{4 a}$ in $76 \%$ yield [Eq. (2)] (Table 1, entry 1). Salicyladehyde $\mathbf{4 a}$ incorporating a phenyl substituent at the $\mathrm{C}_{6}$ position of the ring can be regarded as a 
functionalized biphenyl derivative, and therefore, as a pharmacologically privileged structural motif. ${ }^{[10]}$ The common synthetic approach to salicyladehydes mainly relies on the direct electrophilic substitution of a suitable phenol derivative. From a preparative point of view, this transformation suffers from regioselective drawbacks when the ortho and para positions to the hydroxyl functionality are not conveniently blocked. ${ }^{[11]}$ From this perspective, the direct generation of a 3,6-disubstituted salicylaldehyde derivative is notable.

With a standardized protocol at hand, we next studied the scope of this domino reaction (Table 1). In general, the reaction was tolerant with respect to the type of substitution of the starting PVE. Whereas reaction accommodated different aromatic substituents at the terminal position of the alkyne regardless their electronic nature (entries 1-10), an aliphatic substituent at this position resulted in a diminished yield of the corresponding salicylaldehyde derivative (entry 14). Derivative 3e bearing a benzyl substituent at the propargylic position and a phenyl group at the terminal alkyne position generated the $p$-terphenyl derivative $4 \mathbf{e}$ in excellent yield (89\%, entry 5). Fully substituted propargylic platforms 3k-m afforded the corresponding phenolic ketones 4k- $\mathbf{m}$ in good yields (entries 11-13). In these cases, the use of the methanol scavenger is unnecessary because the corresponding intermediate hemiketals $8 \mathbf{k}-\mathbf{m}\left(\mathrm{R}^{3} \neq \mathrm{H}\right)$ cannot rearrange and they remain in equilibrium with their dienic precursors $7 \mathbf{k}-\mathbf{m}$. Conjugated alkynes 3o-q were also convenient substrates for this reaction, affording the corresponding methyl 2-formyl-3-hydroxybenzoate derivatives 4o-q (entries 15-17). Interestingly, the substitution at the homopropargylic position increased the chemical efficiency of the reaction from $29 \%(\mathbf{4 q})$ to $70 \%(\mathbf{4 o})$ and $56 \%(\mathbf{4 p})$. A silicon substituent at the alkyne position was also tolerated (entry 18), although with diminished efficiency (30\%). Finally, the reaction delivered valuable $o$-fluorophenol derivatives in an easy and efficient manner (entry 7).

With regard to the mechanism of this domino reaction, a working proposal is outlined in Scheme 2. The reaction manifold is launched by the microwave-assisted propargyl Claisen rearrangement of the starting PVE 3 to generate the allenic intermediate 6, which rearranges to the corresponding dienyl intermediate 7 via a thermally allowed pseudopericyclic $[1,3] \mathrm{H}$ shift. ${ }^{[12]} \mathrm{A}$ tandem $4 \mathrm{E} / 4 \mathrm{Z}$ isomerization $[1,5] \mathrm{H}$ shift - enolization reaction affords the key dienyl enol intermediate 11. Finally, electrocyclization and aromatization deliver the phenolic derivative 4. Three 
experimental observations reinforced this mechanistic picture (see SI for details): 1) MW-irradiation of $2 H$-pyran derivative $\mathbf{1 3}^{[3 b]}$ afforded phenol 15 via the well established reversible electrocyclic ring-opening to 1-oxatriene derivative 14 [Eq. (3)]. ${ }^{[13]} 2$ ) MW-irradiation of tetradeuterated PVE derivative $\mathbf{3 q}$ delivered exclusively dideuterated salicylate 4q [Eq. (4)], excluding any H/D scrambling during the process. 3) (E)-dimethyl 2-(pent-2-en-1-ylidene)malonate did not react under the standardized conditions. ${ }^{[14]}$ This finding highlights the importance of the acyl group to modulate the acidity of the allylic hydrogen involved in the double bond isomerization and to provide the required enol 11. Preliminary calculations support this mechanistic picture (see SI for details).

Finally, functionalization of the phenolic products can be easily carried out as exemplified by bromination of $\mathbf{4 a}$ by treatment with N-bromo succinimide ([Eq. (5)].

In summary, we have shown how readily available PVEs 3 can be efficiently converted into convenient multifunctionalized aromatic products via a microwaveassisted and novel domino process involving a key electrocyclization reaction. Efforts directed toward the application of this methodology in natural product synthesis are ongoing in our lab and will be reported in due time.

\section{Experimental Section}

Representative procedure. The microwave-assisted synthesis of salicylaldehyde $4 a$. Propargyl vinyl ether 3a $(0.700 \mathrm{mmol})$ and activated molecular sieves $4 \AA$ (250mg) in dry xylene $(1 \mathrm{~mL})$ were placed in a microwave-special closed vial and the solution was irradiated for 1 hour in a single-mode microwave oven $\left(300 \mathrm{~W}, 200{ }^{\circ} \mathrm{C}\right)$. The reaction mixture was filtrated through a pad of celite using dichloromethane as solvent. After removing the solvent at reduced pressure the products were purified by flash column chromatography (silica gel, n-hexane/EtOAc 95/5) to yield 4a (76\%). m.p. 38.8-39.4 ${ }^{\circ} \mathrm{C}$. ${ }^{1} \mathrm{H}$ NMR $\left(400 \mathrm{MHz}, \mathrm{CDCl}_{3}, 25^{\circ} \mathrm{C}\right): \delta=1.28\left(\mathrm{t},{ }^{3} J(\mathrm{H}, \mathrm{H})=7.2 \mathrm{~Hz}, 3 \mathrm{H}\right), 2.74\left(\mathrm{q},{ }^{3} J(\mathrm{H}, \mathrm{H})\right.$ $=7.2 \mathrm{~Hz}, 2 \mathrm{H}), 6.83\left(\mathrm{~d},{ }^{3} J(\mathrm{H}, \mathrm{H})=7.6 \mathrm{~Hz}, 1 \mathrm{H}\right), 7.34-7.36(\mathrm{~m}, 2 \mathrm{H}), 7.43-7.46(\mathrm{~m}, 4 \mathrm{H})$, $9.84(\mathrm{~s}, 1 \mathrm{H}), 12.22$ (s, $1 \mathrm{H}) \mathrm{ppm} ;{ }^{13} \mathrm{C} \mathrm{NMR}\left(100 \mathrm{MHz}, \mathrm{CDCl}_{3}, 25^{\circ} \mathrm{C}\right): \square \delta=13.6,22.3$, $117.4,121.0,128.0,128.3,130.1,132.0,135.7,137.7,145.0,160.8,197.4$ ppm; IR $\left(\mathrm{CHCl}_{3}\right): \mathrm{v}$ bar $=3021.7,2974.3,2933.3,2880.2,1641.7,1426.1,1316.5,1222.2 \mathrm{~cm}^{-1}$; MS (70 eV): m/z (\%): 226 (100) $\left[M^{+}\right], 225$ (27), 211 (62), 208 (22), 197 (20), 165 (14), 
152 (14).; elemental analysis calcd (\%) for $\mathrm{C}_{15} \mathrm{H}_{14} \mathrm{O}_{2}$ : C 79.62, H 6.24; found: C 7968, H 6.22 .

\section{Acknowledgements}

This research was supported by the Spanish MICINN and the European RDF (CTQ2008-06806-C02-01 and CTQ2008-06806-C02-02), the Spanish MSC ISCIII (RETICS RD06/0020/1046), FUNCIS (REDESFAC PI01/06). G. M.-A. and L. C. thank Spanish MEC for a FPU and FPI grants, respectively. Authors thank Dr. T. Martín, Prof. V. S. Martín for insightful discussions, Prof. F. Cossío for mechanistic advise and Mrs. Anna Jurado for technical assistance.

[1] B. D. Sherry, F. D. Toste, J. Am. Chem. Soc. 2004, 126, 15978-15979.

[2] a) D. Tejedor, A. Sántos-Expósito, D. González-Cruz, J. J. Marrero-Tellado, F. García-Tellado, J. Org. Chem. 2005, 70, 1042-1045; b) D. Tejedor, D. GonzálezCruz, F. García-Tellado, J. J. Marrero-Tellado, M. L. Rodríguez, J. Am. Chem. Soc. 2004, 126, 8390-8391; c) D. Tejedor, G. Méndez-Abt, F. García-Tellado, Chem. Eur. J. 2010, 16, 428-431; d) D. Tejedor, G. Méndez-Abt, F. García-Tellado, Eur. J. Org. Chem. 2010, 6582-6587.

[3] a) M. H. Suhre, M. Reif, S. F. Kirsch Org. Lett. 2005, 7, 3925-3927; b) H. Jiang, W. Yao, H. Cao, H. Huang, D. Cao, J. Org. Chem. 2010, 75, 5347-5350; c) H. Cao, H. Jiang, R. Mai, S. Zhu, C. Qi, Adv. Synth. Catal. 2010, 352, 143-152; d) H. Cao, H. Jiang, W Yao, X. Liu, Org. Lett. 2009, 11, 1931-1933; e) H. Menz, S. F. Kirsch, Org. Lett. 2006, 8, 4795-4797; f) D. Sherry, L. Maus, B. N. Laforteza, F. D. Toste, J. Am. Chem. Soc. 2006, 128, 8132-8133; g) H. Wei, Y. Wang, B. Yue, P-F. Xu, Adv. Synth. Catal. 2010, 352, 2450-2454; h) J. T. Binder, S. F. Kirsch, Org. Lett. 2006, $8,2151-2153$.

[4] PVEs bearing an ester group at the alkyne terminal position behave as catalytic inhibitors of the enzyme DNA Topoisiomerase II. L. León, C. Ríos-Luci, D. Tejedor, E. Pérez-Roth, J. C. Montero, A. Pandiella, F. Garcia-Tellado, J. M. Padrón, J. Med. Chem. 2010, 53, 3835-3839.

[5] A. S. K. Hashmi, Synthesis of Allenes by Isomerisation Reactions, in Modern Allene Chemistry, Vol. 1 (Eds: N. Krause, A. S. K. Hashmi), WILEY-VCH, Weinheim, 2004. 
[6] For a review on the synthesis of hydroxylated arenes, see: D. A. Alonso, C. Najera, I. M. Pastor, M. Yus, Chem. Eur. J. 2010, 16, 5274-5284.

[7] a) Coumarins: Biology, Applications and Mode of Action, (Eds.: R. O_Kennedy, R. D. Thornes), Wiley, New York, 1997; b) Flavonoids: Chemistry, Biochemistry and Applications; (Eds.: O. M Andersen, K. R.; Markham), CRC Press LLC, Boca Raton, 2006; c) S. Bräse,A. Encinas, J. Keck, C. F. Ni, Chem. Rev. 2009, 109, 3903-3990.

[8] For selected reviews, see: a) K. C. Gupta, A. K. Sutar, Coord. Chem. Rev. 2008, 252, 1420-1450; b) J. F. Larrow, E. N. Jacobsen, Top. Organomet. Chem. 2004, 6, 123-152; c) T. Katsuki, Chem. Soc. Rev. 2004, 33, 410-421.

[9] For a precedent for this transformation, see the two steps synthesis of 1,2dihydropyridines described in Reference [2c].

[10]D. A. Horton, G. T. Bourne, M. L. Smythe, Chem. Rev. 2003, 103, 893-930.

[11]For an interesting discussion, see: G. Cozzi, Chem. Soc. Rev. 2004, 33, 410-421.

[12]For a theoretical study of the allene effect in [1,3]H shifts, see: F. Jensen, J. Am. Chem. Soc. 1995, 117, 7487-7492.

[13] a) A. F. Kluge, C. P. Lillya, J. Am. Chem. Soc. 1971, 93, 4458-4463; b) A. F.

Kluge, C. P. Lillya, J. Org. Chem. 1971, 36, 1977-1988; c) Y. Zhu, S. Ganapathy, R. S. H. Liu, J. Org. Chem. 1992, 57, 1110-1113.

[14]For an earlier precedent for this type of experiment, see: W. Fischetti, R. F. Heck, J. Organomet.Chem. 1985, 293, 391-405.

Scheme 1. A branched route to structures $4 \mathbf{a}$ and $\mathbf{5 a}$ from PVEs.

Scheme 2. A mechanistic proposal for the domino process.

\begin{tabular}{cccccc} 
Table 1 & \multicolumn{7}{c}{} \\
\hline Entry & $\mathrm{R}^{1}$ & $\mathrm{R}^{2}$ & $\mathrm{R}^{3}$ & $\mathbf{4}$ & $(\%)^{[a]}$ \\
\hline 1 & $\mathrm{Ph}$ & $\mathrm{Et}$ & $\mathrm{H}$ & $\mathbf{4 a}$ & 76 \\
2 & $\mathrm{Ph}$ & $\mathrm{Pr}$ & $\mathrm{H}$ & $\mathbf{4 b}$ & 72 \\
3 & $\mathrm{Ph}$ & $\mathrm{tBu}$ & $\mathrm{H}$ & $\mathbf{4} \mathbf{c}$ & 67 \\
4 & $\mathrm{Ph}$ & $\mathrm{H}$ & $\mathrm{H}$ & $\mathbf{4 d}$ & 27 \\
5 & $\mathrm{Ph}$ & $\mathrm{Ph}$ & $\mathrm{H}$ & $\mathbf{4 e}$ & 89 \\
6 & $\mathrm{Ph}$ & $\mathrm{PhCH}_{2}$ & $\mathrm{H}$ & $\mathbf{4 f}$ & 61 \\
7 & $\mathrm{Ph}$ & $\mathrm{F}$ & $\mathrm{H}$ & $\mathbf{4 g}$ & 63 \\
8 & $\mathrm{PMeOC}_{6} \mathrm{H}_{4^{-}}$ & $\mathrm{Et}$ & $\mathrm{H}$ & $\mathbf{4 h}$ & 72 \\
9 & $3,4-\mathrm{Cl}_{2} \mathrm{C}_{6} \mathrm{H}_{3^{-}}$ & $\mathrm{Et}$ & $\mathrm{H}$ & $\mathbf{4 i}$ & 77 \\
10 & $p \mathrm{MeC}_{6} \mathrm{H}_{4^{-}}$ & $\mathrm{Et}$ & $\mathrm{H}$ & $\mathbf{4 j}$ & 81 \\
11 & $\mathrm{Ph}$ & $\mathrm{Et}$ & $\mathrm{Me}$ & $\mathbf{4 k}$ & $65^{[b]}$ \\
12 & $\mathrm{Ph}$ & $\mathrm{Et}$ & $n \mathrm{Pen}$ & $\mathbf{4 l}$ & $72^{[b]}$ \\
13 & $\mathrm{Ph}$ & $\mathrm{Et}$ & $\mathrm{Ph}$ & $\mathbf{4 m}$ & $75^{[b]}$ \\
14 & $n \mathrm{mu}$ & $\mathrm{Et}$ & $\mathrm{H}$ & $\mathbf{4 n}$ & $43^{[\mathrm{l}]}$ \\
15 & $\mathrm{CO}_{2} \mathrm{Me}$ & $\mathrm{nPr}$ & $\mathrm{H}$ & $\mathbf{4 0}$ & 70
\end{tabular}




\begin{tabular}{llllll}
16 & $\mathrm{CO}_{2} \mathrm{Me}$ & $\mathrm{Ph}$ & $\mathrm{H}$ & $\mathbf{4 p}$ & 56 \\
17 & $\mathrm{CO}_{2} \mathrm{Me}$ & $\mathrm{H}$ & $\mathrm{H}$ & $\mathbf{4 q}$ & 29 \\
18 & $\mathrm{Me}_{3} \mathrm{Si}$ & $\mathrm{Et}$ & $\mathrm{H}$ & $\mathbf{4 r}$ & 30 \\
\hline [a]Yield of isolated product. [b] Essentially same yields in the absence of molecular sieves $4 \AA$. [c] Diester 5n was also obtained. See \\
SI for details.
\end{tabular}

\section{Text for TOC:}

H makes a difference! A novel reactivity profile of propargyl vinyl ethers biased by the presence of a hydrogen at the homopropargylic position has been developed and conveniently used to construct multifunctionalized phenolic platforms, including salicylaldehydes and the corresponding ketone derivatives.

Keywords: Domino reaction • Propargyl vinyl ethers • Salicylaldehyde• electrocyclization $\cdot$ Allenes 